\title{
REGULAÇÃO, REGULAMENTAÇÃO E FUNÇÃO REGULATÓRIA: DIVERSIDADE DE CONCEITOS ADMINISTRATIVOS
}

\author{
Américo Ribeiro Magro ; Fábio Ferreira Morong ${ }^{2}$ \\ ${ }^{1}$ Universidade Estadual de Londrina - UEL, Mestrado em Direito Negocial, Londrina-PR. ${ }^{1}$ Universidade do Oeste \\ Paulista - UNOESTE, Professor-Doutor,. E-mail: americomagro@hotmail.com
}

\section{RESUMO}

O presente artigo, baseado em estudos anteriores dos autores, busca analisar e traçar as diferenciações necessárias entre conceitos fundamentais do Direito Administrativo e do Direito Regulatório brasileiro, a saber, Regulação, Regulamentação e Função Regulatória. De início, considera, inclusive sob contexto histórico, as origens dos termos analisados no âmbito do direito comparado, notadamente do norte-americano, expondo de que forma os conceitos de "regulation" e "regulator" foram incorporados ao Ordenamento brasileiro com a criação das chamadas agências reguladoras. Em seguida, cuida de diferenciar as terminologias analisadas, com amparo na doutrina, na lei e na Constituição no que tange aos dispositivos concernentes. Conclui, por fim, demonstrando que a natureza compósita função regulatória do estado. $O$ método aplicado foi o dedutivo legal, baseado na interpretação da legislação, jurisprudências, doutrinas e revistas especializadas no tema.

Palavras-chave: Direito Administrativo; Regulação; Regulamentação; Função Regulatória; Administração Pública.

\section{REGULATION AND REGULATORY FUNCTION: DIVERSITY OF ADMINISTRATIVE CONCEPTS}

\begin{abstract}
This article, based on the author' previous studies, seeks to analyze and draw the necessary differentiations between fundamental concepts of Administrative Law and Brazilian Regulatory Law, namely, Regulation, Regulator and Regulatory Function. At the outset, it analyzes, also under historical context, the origins of the terms under the scope of the foreign law, notably the North American law, showing how the concepts of "regulation" and "regulator" were incorporated into the brazilian law with the creation of he so called regulatory agencies. Next, it tries to differentiate the analyzed terminologies, with support of the doctrine, the law and the Constitution, within respect to the devices concerned. Finally, it concludes demonstrating the complex nature of the state's regulatory function. The applied method was the legal deductive, based on the interpretation of the legislation, jurisprudence, doctrines and specialized magazines on the subject.
\end{abstract}

Keywords: Administrative Law; Regulation; Regulator; Regulatory Function; Public Administration. 


\section{INTRODUÇÃO}

Pretende este breve artigo traçar linhas diferenciais entre conceitos da máxima relevância para o Direito Administrativo e Regulatório, isto é, Regulação, Regulamentação e Função Regulatória - os quais, apesar de cognatos, possuem cada qual definição e caracteres próprios na disciplina publicista.

A motivação do estudo decorre, além da importância científica do tema, para a sabida confusão conceitual entre tais terminologias, cuja especificidade, assim como sucede em outros termos, é traço característico do Direito Administrativo.

Assim, num primeiro momento cuida de colacionar as origens terminológicas e hermenêuticas dos institutos analisados no direito comparado, seguido de análise e diferenciação dos mesmos entre si, sempre traçando paralelos com considerações esparsas dos aspectos constitucionais subjacentes.

Cuida, nesse processo, de diferenciar a atividade regulatória e regulamentadora com a jurisdicional - a despeito de doutrina que, a exemplo de Justen Filho, defende que a regulação também se efetiva através intervenção jurisdicional.

Por fim, deixa registrado que não aborda a questão da existência (ou inexistência) do chamado regulamento autônomo, que é objeto de profunda divergência doutrinária.

\section{METODOLOGIA}

O presente trabalho pauta-se pelos métodos histórico e comparativo no que tange à conferição entre a conceituação da doutrina alienígena com a pátria a respeita dos termos analisados. Utiliza, ainda, o método dedutivo para sistematizar os dados coletados, a fim de cumprir o objetivo proposto.

\section{ORIGEM DO TERMO E APARENTES CONOTAÇÕES: REGULATION E REGULATOR}

Antes de compreender a regulação como função do Estado contemporâneo (regulador), cabe solucionar a questão terminológica que envolve a palavra regulação.

A investigação científica sobre a acepção do termo regulação não se deu na doutrina pátria, mas sim em países de língua inglesa, "[...] os quais indicam a atividade desenvolvida pelo Estado de regulation e, para o sujeito que a realiza, regulador" (LEHFELD, 2008, p. 65). A tradução, para o vernáculo, destas expressões implica em algumas dificuldades, considerando que a tradicional concepção de Estado não contempla esta nova competência da Administração. Com efeito, para Calixto Salomão Filho (2001, p. 14), a razão para o problema da definição do termo é simples:

Trata-se da tradicional concepção do Estado como agente de duas funções diametralmente opostas: a ingerência direta na vida econômica e a mera fiscalização dos particulares. A prestação de serviços públicos, de um lado, e a vigilância do mercado, através do poder de polícia, de outro, sempre representaram para os administrativistas a totalidade das funções que o Estado poderia exercer.

Também Alexandre Santos de Aragão observa que a tradução do termo regulação é bastante problemática. Segundo o autor (2004, p. 29):

'Regulation' se traduz usualmente por 'regulamentação', 'regulamento', 'regulação', e 'regra'. Há, portanto, uma assimilação de 'regulation' a 'regulação normativa', ou seja, a produção de normas jurídicas de caráter regulamentar. [...] No sistema norte-americano o termo 'regulation' tem duas acepções distintas, uma mais restrita do que a outra. Em sentido amplo, 'regulation' equivale a todas as atividades dos poderes públicos de organização e configuração da realidade social. Em sentido estrito, todavia, 'regulation' consiste na determinação do regime jurídico de uma atividade econômica. [...] $\mathrm{O}$ poder mais importante do Estado é o da coerção. 'Regulation' é o uso desse poder que tem por finalidade limitar as decisões dos agentes econômicos. 
Ainda sobre pontos semânticos, cabe também diferenciar regulação de regulamentação, conceitos que, apesar da similaridade gráfica não se confundem.

\section{REGULAÇÃO E REGULAMENTAÇÃO: UMA DIFERENCIAÇÃO NECESSÁRIA}

Prosseguindo na linha assumida no tópico antecedente, temos que, a despeito das similitudes gráficas, regulação e regulamentação são conceitos diversos e prestam-se a identificação de institutos que não se confundem. Cabe aqui, portanto, traçar breve, porém relevante, distinção que permita o adequado detalhamento do objeto que esse estudo pretendeu analisar - como deve se dar, segundo as bases assentadas da Hermenêutica, em todos os conceitos que compõem o cabedal de elementos que integram a Ciência Jurídica.

Com efeito, o Direito, sendo Ciência (Jurídica), externa-se por conceitos muito próprios e precisos, elaborados para definir elementos específicos. Em cruas palavras, o que se identifica por um modo, não pode ser reconhecido por outro (a despeito de eventuais semelhanças gráficas ou fonéticas) já que o rigor científico exige precisão no uso da linguagem, o que determina a atuação do operador - com efeito, segundo o conhecido adágio de Ludwig Wittgenstein, autor do indispensável Tractatus Logico-Philosophicus, "os limites da minha linguagem significam os limites do meu mundo".

Cabe, nesse sentido, a precisa definição de Herbert Hart (2009, p. 17), um dos mais conhecidos e memoráveis jusfilósofos, para quem "uma definição é, como a palavra sugere, principalmente uma questão de traçar linhas divisórias ou distinguir entre um e outro tipo de coisa, que a língua demarca pelo uso de palavras distintas".

Pois bem. Feita esta pequena intervenção, cabe-nos verificar a real diferença entre os conceitos de regulação (poder regulatório) e regulamentação (poder regulamentar).

Segundo José dos Santos Carvalho Filho (2010, p. 60), o poder regulamentar ou normativa é "[...] a prerrogativa conferida à Administração Pública de editar atos gerais para complementar as leis e permitir a sua efetiva aplicação". Tal prerrogativa decorre de que o Poder Legislativo, ao editar leis, sem sempre possibilita sua execução. Nesse cenário, cabe, então, à Administração "[...] criar os mecanismos de complementação das leis indispensáveis a sua efetiva aplicabilidade" (CARVALHO FILHO, 2010, p. 60).

Para Diogo de Figueiredo Moreira Neto (2004, p. 132),

[...] sob o aspecto material, a regulamentação é uma função política, no exercício de uma prerrogativa do poder político de impor regras secundárias, em complementação às normas legais, com o objetivo de explicitá-las e de dar-lhes execução, sem que possa definir quaisquer interesses públicos específicos nem, tampouco, criar, modificar ou extinguir direitos subjetivos. De resto, sob o aspecto formal, é uma atribuição de escritíssima previsão constitucional, por isso mesmo, geralmente cometida a chefes de estado ou de governo".

A formalização do poder regulamentar se processa por decretos e regulamentos, expedidos pelo Presidente da República, nos termos do art. 84, IV, da Constituição da República:

Art. 84. Compete privativamente ao Presidente da República:

$[\ldots]$

IV - sancionar, promulgar e fazer publicar as leis, bem como expedir decretos e regulamentos para sua fiel execução;

Existem diversos graus de regulamentação, a depender do local na hierarquia normativa em que se encontre $o$ ato regulamentador. Assim, os decretos e regulamentos podem ser classificados como atos de regulamentação de primeiro grau, ao passo que outros atos que a eles se subordinem - e que, por sua vez, os regulamentem com maior detalhamento -, podem ser qualificados como atos de regulamentação de segundo grau, e assim por diante (CARVALHO FILHO, 2010, p. 61/62) - ad exemplum, as instruções expedidas pelos Ministros de Estado, com o 
fim de regulamentar as leis, decretos e regulamentos, possibilitando sua execução, são exemplos de atos regulamentação de segundo grau.

Salienta-se que a Administração Pública está restrita, no exercício de seu poder regulamentar, à complementação da lei, mas não à sua alteração, a pretexto de regulamentá-la, sob pena de caracterizar abuso de poder regulamentar, que autoriza o Congresso Nacional a "sustar os atos normativos do Poder Executivo que exorbitem do poder regulamentar ou dos limites de delegação legislativa", na forma do art. 49, V, da Constituição Federal.

Conforme se vê, ao desempenhar o poder regulamentar, a Administração exerce inegável função normativa, "[...] porquanto expede normas de caráter geral e com grau de abstração e impessoalidade, malgrado tenham elas fundamento de validade na lei" (CARVALHO FILHO, 2010, p. 60).

Pois bem. Diversamente da regulamentação, a regulação (função regulatória), pelo que foi exposto, é uma função administrativa, que não decorre, portanto, do exercício de uma prerrogativa do poder político, mas, muito pelo contrário, "[...] decorre da abertura, pela lei, de um espaço decisório reservado a uma ponderação politicamente neutra com interesses concorrentes em conflitos setoriais, potenciais ou efetivos" (MOREIRA NETO, 2004, p. 132/133).

Como resume Marcos Juruena Villela Souto (2008, p. 03),

A função regulatória é distinta da função regulamentar porque esta, nos termos da Constituição Brasileira, art. 84, IV, só pode ser exercida pelo Presidente da República. Embora muito se fale na existência, no âmbito das agências reguladoras, de um 'poder regulamentar amplo', essa não é a expressão adequada, posto que privativo do Chefe do Poder Executivo. Ademais, enquanto o regulamento é ato informado por critérios políticos de detalhamento da lei, a norma regulatória explicita conceitos jurídicos indeterminados, implícitos na lei.

Apesar da diferenciação que aqui se delineou, há vozes discentes na doutrina especializada sobre a pertinência desta distinção. Ad exemplum, para José dos Santos Carvalho Filho (2010, p. 63),

a despeito da distinção entre os modeles, parece-nos não existir erronia no emprego da expressão poder regulamentar para ambos. É que tanto num como noutro caso, o órgão administrativo está complementando a lei e possibilitando a sua execução, o que, em última instância, se configura como objeto do poder regulamentar.

Verificadas tais observações iniciais, cabe conceituar o instituto da regulação.

\section{OS TIPOS REGULATÓRIOS DE VITAL MOREIRA E A CONCEITUAÇÃO DO INSTITUTO}

$\mathrm{Na}$ busca por um conceito jurídico satisfatório para definir o instituto da regulação, é inevitável socorrer-se das lições de Vital Moreira (1997, p. 34) que, de forma resumida, consegue destacar três linhas de concepções, intituladas tipos regulatórios, aplicáveis ao vocábulo regulação, que norteiam o entendimento dos autores brasileiros e estrangeiros. São elas: (I) no sentido amplo, regulação seria toda forma de intervenção do Estado na economia, independentemente de seus instrumentos e fins; (II) no sentido menos abrangente, a regulação seria a intervenção estatal na economia por outras formas que não a participação direta na atividade econômica, equivalendo ao condicionamento, coordenação e disciplina da atividade econômica privada; e (III) no sentido estrito, a regulação seria somente o condicionamento normativo da atividade privada, seja por lei ou qualquer outro instrumento normativo (ARAGÃO et al, 2006, p. 146).

Segundo Marçal Justen Filho (2004, p. 49), os tipos regulatórios elaborados por Vital Moreira são de grande contribuição para a adequação das definições doutrinárias relativas ao instituto da regulação, considerando tais tipos como "[...] modelos de organização estatal 
relativamente à partilha de competências regulatórias em face da organização interna do Estado e da relação com entidades extra-estatais". Conforme explica o autor (2004, p. 50),

[...] no âmbito da organização estatal, as competências regulatórias são distribuídas segundo um critério de concentração, o que pode conduzir a um acúmulo de poderes em âmbito central. Mas também podem ser instituídas outras órbitas de poderes estatais orientadas a promover a regulação (tal como as agências reguladoras independentes). Admite-se, ademais disso, a regulação por entidades não estatais (o que poderia colocar a séria dúvida sobre a natureza das entidades reguladoras de profissões reconhecidas em face do Direito brasileiro). Isso permitiria diferenciar várias formas de conjugação de três núcleos teóricos da atribuição das aludidas competências, que são os órgãos estatais propriamente ditos, as agências e a chamada autorregulação.

Dentre os tipos regulatórios elaborados por Vital Moreira, pode-se dizer que parte considerável da doutrina pátria opta por adotar o terceiro sentido, "[...] que correlaciona a regulação a todo tipo de intervenção do Estado na economia, seja por meio direito ou indireto, sem limitação de forma" (ARAGÃO et al, 2006, p. 147);

Com base nisso, temos mais acertada a definição elaborada por Alexandre Santos de Aragão (2004, p. 37), para quem

[...] a regulação estatal da economia é o conjunto de medidas legislativas, administrativas e convencionais, abstratas ou concretas, pelas quais o Estado, de maneira restritiva da liberdade privada ou meramente indutiva, determina, controle ou influencia o comportamento dos agentes econômicos, evitando que lesem os interesses sociais definidos no marco da Constituição e orientando-os em direções socialmente desejáveis.

Em resumo, pode-se dizer que a regulação "[...] engloba todas as formas de organização da atividade econômica através do Estado, seja a intervenção através da concessão de serviço público ou o exercício do poder de polícia" (SALOMÃO FILHO, 2001, p. 14). Assim, consiste na "atividade estatal de intervenção indireta sobre a conduta dos sujeitos públicos e privados, de modo permanente e sistemático, para implementar as políticas de governo e a realização dos direitos fundamentais" (JUSTEN FILHO, 2012, p. 637).

\section{A REGULAÇÃO COMO FUNÇÃO COMPÓSITA DO ESTADO}

$\mathrm{Na}$ busca por um conceito jurídico satisfatório para definir o instituto da regulação, é inevitável socorrer-se das

Considerando a definição acima exposta, temos que a regulação constitui legítima função do Estado (daí que se falar em função reguladora ou função regulatória), que se expressa em "um híbrido de atribuições de variada natureza: informativas, planejadoras, fiscalizadoras e negociadoras, mas, também, normativas, ordinatórias, gerenciais, arbitradoras e sancionadoras" (MOREIRA NETO, 2003, p. 107). Em outras palavras, trata-se de um dos tipos de atividade estatal, que se traduz tanto no desempenho de função legislativa, jurisdicional e de controle, não se restringindo, apenas, ao exercício da atividade administrativa (muito embora seja este o objeto do presente estudo).

Neste exato rumo, Alexandre Santos de Aragão (2004, p. 24) argumenta que a regulação implica na integração de diversas funções, pressupondo que "um quadro seja imposto às atividades econômicas, devendo respeitar um certo equilíbrio dos interesses das diversas forças sociais presentes". Segundo o autor (2004, p. 24),

[...] este quadro normativo é estabelecido por decisões gerais e abstratas, constantes geralmente de regulamentos; pela aplicação concreta das suas regras e pela composição dos conflitos que delas advêm, dando lugar, nestas duas últimas hipóteses, a decisões individuais. Há, portanto, três poderes inerentes à regulação: aquele de editar a regra, o de assegurar a sua aplicação e o de reprimir as infrações. 
Assim, a função regulatória é tida por compósita, pois é complexamente composta de diversos poderes que, ao cabo e em interação, influem na atividade regulatória da economia em si (tipo regulatório em sentido estrito) e consistem na edição da regra reguladora, sua aplicação no caso concreto e a repressão a sua infração.

\section{CONCLUSÃO}

A par da presente pesquisa, pretendeu-se estabelecer as linhas divisórias entre conceitos fundamentais do Direito Administrativo e Regulatório, isto é, regulação, regulamentação e função regulatória; os quais, no entanto, persistem objeto de inaceitável confusão no âmbito da práxis e da jurisprudência.

A preocupação em talhar adequadamente tais definições não é preciosismo inútil, malgrado se conviva hoje com segmentos da Ciência Jurídica revoltosos dos ditos "formalismos" da linguagem dos operadores, considerada demasiado "empolada". Ora, o Direito é também Ciência aplicada e, como tal, expressa-se por métodos próprios que, como decorre de sua própria natureza técnica, demandam termos em linguagem também específica. Esta linguagem - assim como sucede com outros sinais, assunto ao qual não se aventurou, dado constituir objeto de larga e competente doutrina - define os limites da Ciência Jurídica, embora não se possa olvidar da questão dos limites da linguagem, sobretudo à luz do pensamento de Wittgenstein.

Sem embargo, é preciso combater os excessos que, pretendendo clareza, constituem falsa erudição e prejudicam a compreensão dos leitores e ouvintes em geral; devem ser evitados e combatidos, eis que igualmente prejudiciais à precisão da linguagem.

Sem embargo das considerações conceituais tecidas, não se pode olvidar que a Constituição de 1988 introduziu um novo modelo do que segmentos da doutrina publicista convencionam de "Estado Regulatório" - sobretudo à luz da instituição das Agências Reguladoras e do Plano Nacional de Desestatização (PND) que se seguiu à Carta. Ainda assim, possua viés liberal ou intervencionista, o Estado, por sua própria natureza, sempre exerce atividade interventiva de alguma ordem e escala, em especial no caso brasileiro, em que o Estado ainda é um "relevante" agente econômico, notadamente pela razoável (e questionável) quantidade de empresas estatais e de economia mista.

\section{REFERÊNCIAS}

ARAGÃO, Alexandre Santos de. Agências reguladoras e a evolução do direito administrativo econômico. 2. ed. Rio de Janeiro: Forense, 2004.

CARVALHO FILHO, José dos Santos. Manual de direito administrativo. 23. ed., rev., ampl. e atual. Rio de Janeiro: Lumen Juris, 2010.

HART, Hebert Lionel Adolphus. O conceito de direito. 1. ed. São Paulo: Martins Fontes, 2009. JUSTEN FILHO, Marçal. Curso de direito administrativo. São Paulo: Saraiva, 2012.

LEHFELD, Lucas de Souza. Controle das agências reguladoras. São Paulo: Atlas, 2008.

MOREIRA NETO, Diogo de Figueiredo. Direito regulatório: a alternativa participativa e flexível para a administração pública de relações setoriais complexas no estado democrático. Rio de Janeiro: Renovar, 2003.

MOREIRA, Vital. Auto-Regulação Profissional e Administração Pública. Coimbra: Almedina, 1997. SALOMÃO FILHO, Calixto. Regulação da atividade econômica. São Paulo: Ed. Malheiros, 2001. 
SOUTO, Marcos Juruena Villela. Função Regulatória. Revista Eletrônica de Direito Administrativo Econômico (REDAE), Salvador, Instituto Brasileiro de Direito Público, no 13, fevereiro/março/abril, 2008. Disponível na Internet: <http://www.direitodoestado.com.br>. Acesso em: 05/10/2018.

SUNDFELD, Carlos Ari. Fundamentos de direito público. 4. ed., rev., aum. e atual. São Paulo: Malheiros, 2000. 